Volume 6, Issue 1, January 2021, pp. 46 - 58

DOI: $10.23917 /$ jramathedu.v6i1.11449

p-ISSN: 2503-3697, e-ISSN: 2541-2590

\title{
Rubric as a learning tool in teaching application of derivatives in basic calculus
}

\author{
Leah Conejos Auxtero ${ }^{1 *}$, Roar Abalos Callaman² \\ ${ }^{1}$ Department of Senior High School, University of Mindanao, Philippines \\ ${ }^{2}$ College of Education, University of Southeastern Philippines, Philippines \\ *Corresponding Author: auxteroleng04@gmail.com
}

\begin{tabular}{l}
\hline ARTICLE INFO \\
\hline Article history: \\
Received: 8 July 2020 \\
Revised: 15 November 2020 \\
Accepted: 26 November 2020 \\
Published online: 23 \\
December 2020 \\
Published regularly: January \\
2021
\end{tabular}

Keywords:

Rubrics, learning tool, effectiveness

\begin{abstract}
Rubric has been associated with the term assessment used for grading and/or scoring. However, it might observe less, but it is also designed as students 'learning tool. This study was conducted to provide empirical facts on its effectiveness as a learning tool in teaching Applications of Derivatives in Basic Calculus. It used the quasi-experimental design called the pretest posttest design. The participants were the 96 students from two classes of Grade 11 STEM students at the University of Mindanao. The instruments used were the adapted and improved rubric designed from two different research, a 25-item teacher-made problem-solving test questionnaire that was used in both pretest and posttest to measure the performance of the experimental and control group. The test questionnaire and rubric were both validated by 3 experts in the field with a result of very good, and it has a good internal consistency. The data gathered were summarized, translated, and analyzed using the mean scores of pretest and posttest. Findings showed that both the experimental and control group showed improvement, however, the experimental group who used rubric as a learning tool showed more significant improvement than control group. Thus, using a rubric as a learning tool in teaching Applications of derivatives is effective in improving students' academic achievement as it teaches students to develop their understanding of procedural knowledge.
\end{abstract}

(C)2020 Universitas Muhammadiyah Surakarta

\section{Introduction}

One of the main goals of mathematics education is to teach problem solving and apply the concept in real-life setting (Gurat, 2018). Problem solving is one of the most important skills a student should acquire in studying Mathematics (Wilson, Fernandez, \& Hadaway, 2011). It is also a skill which is an indicator of one's readiness to advanced degrees and ultimately the country's innovative capacity (Oliveros, 2014). According to Rickard as cited by Hammond, Flook, Harvey, Barron, and Osher (2020), it continues to be a chief focus of K-12 mathematics education reform since it is one of the skills that is needed to develop in the primary education years. Moreover, it is also one of the key components, which requires the highest level of mathematical knowledge and skills (Bradbury, 2010). However, according to Callaman and Itaas (2020), one of the underlying reasons why students do not like math is the idea that they could not see the usefulness in their daily 
lives. This showed that the goal of teaching problem solving failed. According to Dendane as cited by Gurat (2018), teaching problem solving and acquiring problem-solving skill are some of the most challenging topics to teach and learn. For this undeniably, students showed an evident difficulty in worldwide assessment performance in mathematics specifically solving word problems.

In the report of Education Quality and Accountability Office (EQAO) from 2013 to 2014, there were struggles in problem-solving and low math literacy scores among students of Ontario, Canada. According to EQAO report as cited by Palmay (2015), most significantly, within the past five years, mathematics assessment result has dropped from $71 \%$ to $67 \%$ in the Primary Division. On the other hand, the result dropped from $61 \%$ to $54 \%$ in the Junior Division. In addition, in Turku, Finland, Pongsakdi, Laine, Veermans, Hannula-Sormunen, and Lehtinen ( $\underline{2016})$ found out that giving problem sets as a periodical project improved the performance of the students in both computational and problemsolving skills; however, students still perform low in the national and international levels of Mathematics and science.

Moreover, Philippines also got a poor ranking in 2018 PISA result with a mean score of 353 points in Mathematical Literacy, which is below the average of 489 points. This is alarming because mathematical literacy as described by OECD (2017) is the ability and/or students' skills to analyze things, reason out and explain circumstances, and communicate ideas effectively as they do math by posing, formulating, solving, and interpreting solutions to mathematical problems. Moreover, according to DepEd - National Report of the Philippines (2019), Philippines ranked 78th out of 79 participating countries. On the other hand, in the same assessment, Singapore still ranked first consistently which has mathematical problem solving. Relatively, the poor performance of the Philippines was brought by how mathematics was taught, which was according to Limjap as cited by Tupas (2012), it usually starts with teaching rules and steps on how to solve the problem then followed by board work and/or seatwork. For this, students have limited time spent in exposure to various mathematical problems.

In addition, Mathematics educators of the University of Mindanao raised a problem that a transition from senior high school (STEM) to college and problem-solving related courses were not rigid due to the academic demands to learning. Further, the academic performance of Grade 11 STEM students at the University of Mindanao in the first semester of the academic year, 2019-2020, in the subject Pre-calculus showed that almost 65\% of them have had difficulty with problem-solving. A similar case is observed in the three previous batches wherein students' performance in their fourth quarter examination, which the coverage was Application of Derivatives, showed that $42 \%, 54 \%$ and $46 \%$ failed the said examination, respectively.

Based on the present investigation made on the status of mathematics education globally and locally, there is a need to address the challenge on improving students' achievement in Mathematics by developing their problem-solving skills. It is in support of the Department of Education's K to 12 Curriculum System Math Framework, which emphasizes critical thinking skills and problem solving. Thus, the study was conducted to determine the effectiveness of rubrics as a learning tool in teaching Applications of Derivatives in Grade 11 STEM students at the University of Mindanao. More specifically, it sought to identify the pretest and posttest mean scores with their significant differences, the mean gain scores, and the effect of class size. Moreover, the null hypotheses were tested at 0.05 alpha level of significance that there are no significant differences between the pretest and posttest mean scores of each group and there is no significant difference between the mean gain scores of the experimental and control group. 
Evidently, one of the subjects of the K-12 Program for Science and Technology Engineering and Mathematics (STEM) students is Basic Calculus. This subject aims that learners shall be able to formulate and solve situational problems accurately involving applications on derivatives. In the curriculum guide of the said subject, the topics under the applications of derivatives include illustrations of a tangent line to the graph of a function at a given point, solving optimization problems, and solving situational problems involving related rates, and rectilinear motion. Moreover, these word problems include the applications of differentiation rules in computing the derivative of an algebraic function, exponential functions, and logarithmic functions. However, there was a great emphasis on related rates and rectilinear motion, which is prerequisite skill in finding area of a certain region. To solve such problems, students should be equipped with the basic rules and concepts of differentiation.

In the study of Gallego-Arrufat and Dandis (2014), the findings showed that rubrics can enhance learning because it made the students play an active part in the learning process since they worked hard to achieve the required level/step. Moreover, Brookhart (2013) presented one of the importance of rubric to improve learning is by using it as an involved and stimulating method of learning, where in the ideal situation a student would not read a rubric once, but use it to reflect, develop and analyze. In addition, a rubric provides a "feed forward mechanism" when rubrics are used by both students and teachers alike, meaning a rubric can encourage the student to reflect on their job and concentrate on how to improve in the future (Cox, Morrison, \& Brathwaite, 2015).

In addition, research has shown that timely feedback makes learning easier, when it is sent back to the students shortly after the assignment is done, and it is most successful (Stevens \& Levi, 2013). Similarly, rubrics also allow students to interpret and predict expected levels of output more effectively when presented to students before and during learning (Tractenberg, Attwood, \& Via, 2019). According to Andrade as cited by Donlan (2014), rubric promotes thinking and learning and these are beneficial to the students who receive rubric to direct their valuable learning. Rubric help students acquired knowledge by deciding a strategy on what method to apply in achieving a solution (Sonseca, Sahuquillo, Martinez-Casas, Carballeira, Denia, \& Rodenas, 2015).

This study would benefit the students to have an opportunity to discover more ways to learn solving problems and develop their problem-solving skills. Moreover, through this study, teachers and school administrators would consider enriching the use of innovative materials in teaching mathematics by providing opportunities to students to use tools in maximizing learning in different and new possible ways. Also, there have been several studies and literature about the rubric as an assessment tool (Raposo, De La Serna, \& Martinez- Figueira, 2014; Cox \& Brathwaite, 2015; Garfolo, 2016; and Muhammad, Lebar \& Mokshein, 2018); rubric as a teaching tool (Andrade \& Reddy, 2010; and Reynolds-Keefer, 2010; Lucander, Knutsson, Salé, \& Jonsson as cited by Jonsson, 2014; and Gulikers and Oonk, 2019).

Moreover, rubric conforms on the constructivism philosophy of Jean Piaget, in which students learn by integrating new information with what they already know (Behera, 2017). Constructivist learning theory had a broad influence on teaching methods which was underlying theme of many reform movements in education (Bada, 2015). It implied that in following the steps of solving a problem, rubric should be an instrument of mental construction. Since the theory suggests that humans construct information and meaning from their experiences, rubric is a learning tool for students to derive from experience, as it is a new strategy for problem-solving learning. Moreover, Jonsson and Svingby as cited by Jeong (2015) simplified it into two purposes; one is to assist the evaluator in achieving an 
accurate judgment; and the other one is to facilitate the learning of both parties through constructive feedback. Thus, rubrics are tracker of performance. However, none of these researchers provided clear pictures of the rubric as a learning tool, and this type of study seldom conducted to senior high school students, mainly on the calculus subject. Thus, to fill the gap, this research investigates the effectiveness of rubric as a learning tool in teaching the application of derivatives in Basic Calculus to the students' performance.

\section{Research Methods}

\section{Research Design}

This study utilized a quasi-experimental research design, especially the type of pretest-posttest. This is the best approach to be used in comparing two groups, which are the control and experimental group Creswell (2014). In quasi-experimental, pretest was administered to both groups, conducts experimental treatments only to the experimental group, and administers posttest to both groups. The collection of research studies, results, and interpretation of research findings were used as primary data.

\section{Research Locale}

This study was conducted at the University of Mindanao academic year 2019-2020. Purposive sampling convenience was used, and the two sections were classes from Grade 11 STEM strand who have Basic Calculus as their subject in the second semester of the said academic year in which one class had 49 students and the other class had 47 students.

\section{Research Instruments}

The rubric was adapted and improved from Gleason (ㅁ13) in his study entitled "Assessment of Students' Critical Thinking and Problem-Solving Abilities" and Malang (ㅁ16) in her study "Effectiveness of a Rubric as a Learning Tool in Teaching Mathematics of Investment. This rubric contained the steps in problem-solving and the target skills that the students need. Also, test questions were utilized, which are part of the curriculum guide and has a portion on the final examination in the subject of Senior High School Basic Calculus. It has 25 questions which were composed of the topics in Application of Derivatives which are applying the differentiation rules in computing the derivative of an algebraic, exponential, and trigonometric functions; solving optimization problems; and solving situational problems involving related rates. The test questionnaire was used as an instrument to utilize the pretest and posttest to determine the students' academic achievement in the said mathematics topic before and after the experiment. The experts validated the said instrument with a very good descriptive result and tested its reliability with a Cronbach's value of .857 and administered to 96 Grade 12 STEM students who have taken the subject. After the results were gathered, the instrument was revised with the same number of items with some revisions in the choices of the instruments. To interpret the scores of the students were interpreted if it was outstanding, very satisfactory, satisfactory, poor, and very poor.

\section{The procedure of the study}

When the endorsement letter was secured, next step was manual online search for the studies to be included in the analysis after the focus was clearly defined. Then, instruments were validated, and the researcher conducted a pilot testing. After that, the assignment of group was identified through tossing a coin which according to McKenzie (2019) that the toss of a coin is a valid randomization method.

The experimental and control group were taught under the same lesson plan. The list of activities per session. In the first session, the experimental group was introduced to the 
rubric. The experimental group received a conventional method of teaching with a group activity in which students used rubric for familiarization of the instrument. On the second and third topic, the experimental group had a pairing activity to practice more on the use of the rubric. In the rest of the remaining session, the experiment group was given task with the used of rubric individually. However, the control group only received the conventional method without the use of rubric. The same test was administered to the control and experimental group after the conduct of the experiment. The instrument used in posttest was also the same in pretest but with some revisions such as changing of the arrangement of questions to avoid threats to internal validity (Creswell, 2014).

\section{Data Analysis Techniques}

The data gathered from the pretest and post-test were tabulated for data analysis. The following statistical tools were used for computation and analysis of data. These are mean score, standard deviation, t-test for independent samples and effect size. Mean score was used to determine the mean value of the pretest and posttest scores of the participant. Moreover, standard deviation was used to know how dispersed the scores of the experimental and control group. Also, t-test for independent samples tool was used to measure the significant difference between the pretest and posttest scores of the two groups; and the hypothesis testing was used based on an alpha 0.05 level of significance. Lastly, the effect size of a t-test was used to determine the degree of effectiveness of the treatment.

\section{Results and Discussion}

\section{Utilization of rubric}

Rubric as learning tool was presented to the experimental group as a treatment of this experiment. In the first try, the students were grouped into five to help one another in getting familiarization with the steps. The procedure is that a word problem will be given to the students, then they will write the steps on how they solve it but they should relate their solutions on the standard criteria listed on the rubric. After that, the students will present their output and students will rate on what criteria their output belongs. On the second session, the students did a pairing activity which undergone the same process except for the presentation part. Lastly, for the rest of the topics, the students did the activity individually. The teacher served as a facilitator of the activity and students guide their selves using the rubric as their learning tool in familiarizing the steps in solving word problems in Applications of Derivatives in Basic Calculus. The results and discussion presented below showed the findings in utilizing the rubric as a learning tool.

\section{The pretest means scores of the control and the experimental group}

Table 2 presents the pretest mean scores of the control group and the experimental group. Data shows the prior knowledge of the two groups before the start of the experiment.

Table 2

Pretest means scores of control and experimental group

\begin{tabular}{cccccc}
\hline Groups & $\mathrm{N}$ & Mean & Std. Deviation & $\begin{array}{c}\text { Confidence } \\
\text { Interval }\end{array}$ & Description \\
\hline Experimental Group & 49 & 8.45 & 2.56 & $8.45 \pm 0.717$ & Poor \\
Control Group & 47 & 9.32 & 2.98 & $9.32 \pm 0.852$ & Poor \\
Overall Mean & 96 & 8.87 & 2.79 & $8.87 \pm 0.558$ & Poor \\
\hline
\end{tabular}


The pretest mean scores of the experimental and control group are 8.45 and 9.32, respectively. This implies that the control group has a higher score than the experimental group. Moreover, the overall result of the pretest mean scores of the control and experimental group is 8.45 out of 25 item questionnaires, which implies that their scores are poor. Thus, they demonstrate evidence of basic problem-solving skills but require assistance. Moreover, the standard deviation of the experimental and control group is 2.56 and 2.98, respectively. This implies that the experimental group has a lower standard deviation, which means that data are more homogenous than the control group. Both groups showed a low score in the pretest. The preceding statistical figures suggest that there is an observable difference in the level of the pre-test mean scores of the two groups involved in the study. It further indicates that before the implementation of the treatment, the level of the students' ability to answer the test questions about applications on derivatives is on the same level.

\section{The posttest mean score of control and experimental group}

Table 3 presents the posttest mean scores of the control group and the experimental group. Data shows the achievement of the two groups after the conduct of the experiment.

Table 3

\begin{tabular}{cccccc}
\multicolumn{6}{c}{ Posttest mean score of control and experimental group } \\
\hline Group & $\mathrm{N}$ & Mean & Std. Deviation & $\begin{array}{c}\text { Confidence } \\
\text { Interval }\end{array}$ & Interpretation \\
\hline Experimental Group & 49 & 15.41 & 3.84 & $15.41 \pm 1.075$ & Very Satisfactory \\
Control Group & 47 & 13.06 & 3.23 & $13.06 \pm 0.923$ & Satisfactory \\
Overall Mean & 96 & 14.26 & 3.73 & $14.26 \pm 0.746$ & Satisfactory \\
\hline
\end{tabular}

The score showed that the students' academic achievement has been measured through the posttest, and the result showed that the experimental and control group has 15.41 and 13.06, respectively. This implies that the experimental group has a very satisfactory score after the group received the treatment, by using the rubric as a learning tool. Thus, they demonstrate substantial problem-solving skills. Moreover, though the scores of the control group increased after the group received the conventional method without the use of rubric, their mean score is at the satisfactory level. Thus, they demonstrate adequate problem-solving skills. On the other hand, the standard deviation of the experimental and control group is 3.84 and 3.23, respectively. It implies that the control group has a lower standard deviation, which means that data in control group are more homogenous than the experimental group.

The overall mean score of the two groups in their posttest achievement is 14.26, which is satisfactory. This implies that the students demonstrate adequate problem-solving skills. Thus, it showed that indeed, there was an improvement after the conduct of experiment in the problem-solving skills of the students. It is supported by Andrade and Reddy (2010) study that rubrics are learning tools, which encourage them to encourage actively. In addition, the research on rubrics and adult learners 'assessment, which showed that rubrics helped students improved their performance specifically in solving critical word problems (Bolton, as cited by Kinne, Hasenbank \& Coffey, 2014). Moreover, this also supports the research on student's perspective on rubric-referenced assessment, which showed that rubric helped students, achieved better performance and contributed to have good quality of work (Andrade \& Reddy, 2010). 
The mean gain scores of control and experimental group

Table 4 presents the mean gain scores of the control and experimental group after the conduct of experiment. Table presents the variable being tested, which are the teaching strategy and the academic achievement of the students. Moreover, it presents the mean gain scores together with the percentage increase of the scores.

Table 4

Mean gain scores of control and experimental group

\begin{tabular}{cccc}
\hline \multicolumn{2}{c}{ Experimental } & \multicolumn{2}{c}{ Control } \\
\hline Mean & \% Gain & Mean & \% Gain \\
\hline 6.96 & $82.37 \%$ & 3.75 & $40.24 \%$ \\
\hline
\end{tabular}

The mean gain score of the experimental group is 6.96 while the mean gain score of the control group is 3.75. These gains in terms of percentage increase are equivalent to $82.37 \%$ for the experimental group and $40.24 \%$ for the control group. It shows that there is a more significant increase in the mean gain scores of experimental groups compared to the control group. This implies that the use of rubrics in the learning process teaches a learner to develop an understanding of the expectations and components of a particular task given. This also makes a learner aware of his or her learning progress and process. Therefore, this confirms the rubric is one that lets teachers not only accurately assess the work of students but also help students learn unique skills and knowledge (Bargainnier, as cited by Raymond, Alkrisat, \& Hebda, 2018).

The effect class size in this study is 0.67. It implies that the treatment has a large effect on the achievement of the students. Indeed, rubrics have shown that it can serve two purposes. One is to assist the evaluator in achieving an accurate judgment. The other one is to facilitate the learning of both parties through constructive feedback. Thus, rubrics are tracker of performance (Panadero \& Jonsson, 2016). Apart from that, the rubric, in accordance with Jean Piaget's constructivist philosophy is a teaching and learning approach based on the premise that cognition (learning) is the product of "mental construction." In other words, students learn by using their schema to fit into the new information.

In addition, rubric, concerning Zone of Proximal Development of Lev Vygotsky, refers to what a learner can achieve without help or what he/she can do with guidance and/or encouragement of a skilled individual. Moreover, rubric, by Instrumental Understanding and Relational Understanding of Richard Skemp further supports the study wherein a child understands the rules and procedure if there are instruments use to help student builds schema (Skemp, 1976). Thus, the rubric would be an iconic tool in Bruner's Discovery Learning to guide students in the procedures in solving the problem.

\section{Significance of Difference on Test of Scores on both the Experimental and Control Group}

Table 5 is composed of 5 tests which test the significance of difference on test of scores on both the experimental and control group. The description of each test is presented below.

Table 5

Significance of difference

\begin{tabular}{lccc}
\hline \multicolumn{1}{c}{ Test on the } & t-value & p-value & Interpretation \\
Significance of Difference between & & & \\
\hline $\begin{array}{l}\text { Pre-test Mean Scores of Experimental and } \\
\text { Control Group }\end{array}$ & -1.537 & .473 & Accept $H_{o}$ \\
$\begin{array}{l}\text { Posttest Mean Scores of Experimental and } \\
\text { Control Group }\end{array}$ & 3.232 & .033 & Reject $H_{o}$ \\
\hline
\end{tabular}


Table 5 (Continued)

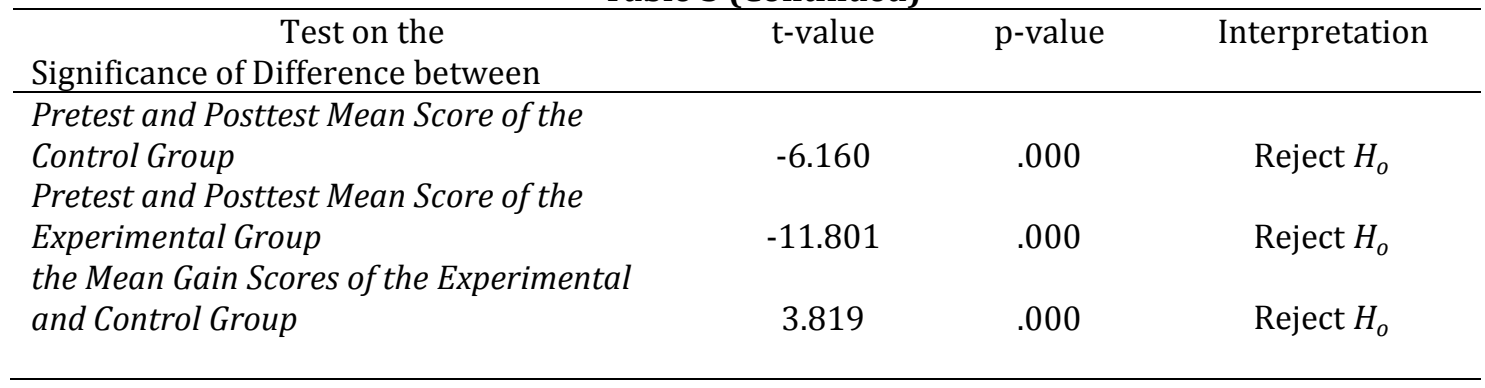

In the test on the significance of difference between pre-test mean scores of the experimental and control groups, Table 5 showed that the p-value is .473, which is above the alpha value of 0.05; thus, it accepts the null hypothesis of the study. This means that there is no significant difference between the pretest mean scores of control and experimental groups. This implies that before the experiment, both the experimental and control group are equally likely in terms of prior knowledge before the start of the experiment. The results show that both groups are ideal for this study because each group has more or less on the same level. According to Kumar (2014), it is favorable if all the "before" data (pre-test) of the different variables are more or less on the same level; or that there is no significant difference between the control group and the experimental group.

In the test on the significance of difference between posttest mean scores of experimental and control group, the table showed that the $\mathrm{p}$-value is .033 , which is below the alpha value of 0.05 ; thus, it rejects the null hypothesis of the study. It shows that there is a significant difference between the posttest mean scores of control and experimental groups. It implies that after the experiment, both the experimental and control groups are significantly different in terms of gained knowledge after the conduct of the experiment. The results showed that the use of rubric as a teaching strategy has a significant difference in the traditional way of teaching or the conventional method of teaching problem-solving. This particular finding is a favorable condition that warrants the experimentation process; then, the treatment is found to be effective.

This is supported by the Discovery Learning Theory of Jerome Bruner (Clabaugh, 2010) in which rubric would be an iconic tool to guide students in the procedures in solving the problem. In addition, according to Park as cited by Philominraj, Bertilla, Muñoz and Fuentealba (2018), students who not only learn better through the active learning approach but also enjoy a great deal from the learning experience. Thus, the significant difference between the scores is evident in the result of the study. The result also conforms the results of Andrade and Reddy (2010), suggesting that students who used rubrics reported greater satisfaction and learning. It also conforms the analysis of Petkov \& Petkova as cited by Francis, (ㅁ18) which suggests that the group that used rubrics received significantly higher grades than the students in another group who did not use rubrics.

In the test on the significance of difference between pre-test and posttest mean score of the control group, the result showed that the p-value is .000, which is below the alpha value of .05; thus the null hypothesis is rejected. This implies that there is a significant difference in the scores on the pretest and posttest mean scores of the control group. This shows an improvement in the control group after receiving a conventional way of teaching since students are already exposed to the topic. Thus, students are now able to relate the essence of the model to the essence of the concept and equate or transfer specific conceptual aspects from one domain to another. It supports the study of Language policy, multilingual education and power in Rwanda in which it was found that conventional 
teaching was suited to improving the performance of seventh grade students in abstract principles than independent work approaches alone (Samuelson \& Freedman, 2010). Thus, conventional method helped improve student's achievement.

In the test on the significance of difference between the pretest and posttest mean score of the experimental group, the result showed that the p-value is .000 , which is below the alpha value of .05; thus, the null hypothesis is rejected. It implies that there is a significant difference in the scores on the pretest and posttest mean scores of the experimental group. This is a favorable result because it showed that the scores of the experimental and control groups have a significant difference which implies that the intervention between two groups was effective. Moreover, it conforms to the study of Reitmeier, Svendsen, and Vrchota (2004) which showed that there was a significant difference of scores of the group of students. The group of students who used rubrics has a mean score of $94 \%$, while the group that did not use rubric has a mean score of $86 \%$.

In the test on the significance of difference between the mean gain score of the experimental and control group, the table showed the p-value is .000, which is lower than the alpha value of .05. It means that the null hypothesis is rejected, thus, there is a significant difference between the mean gain scores of the experimental and control group. It implies that the experimental group did better than the control group; hence, the use of rubrics as a learning tool is better than the conventional way. It then supports the idea of the effectiveness of a rubric as a learning tool as rubrics make the learning target clearer. Thus, it conforms that rubric also helps provides more accurate and objective assessments, evaluations and rating that can avoid subjective grading scheme to the performance of the students (Raposo, De La Serna, \& Martinez- Figueira, 2014).

The effect class size in this study is 0.67 . It implies that the treatment has a large effect on the achievement of the students. Indeed, rubrics are tracker of performance (Panadero \& Johnson, 2016). Apart from that, the rubric, in accordance with Jean Piaget's constructivist philosophy, is a teaching and learning approach based on the premise that cognition (learning) is the product of "mental construction." In other words, students learn by using their schema to fit into the new information. Since the result showed that the use of rubric as a learning tool in learning Applications of Derivatives has large improvement in enhancing student's academic achievement, thus it conforms to the constructivism theory of Jean Piaget in which rubric is an instrument of mental construction (Zhou \& Brown, 2017). It also agrees to the zone of proximal development of Lev Vygotsky in which rubric should act as qualified aid in assessing the problem-solving skills of the students $(\mathrm{Yu}, \mathrm{Hu} \&$ Zhang, 2013). Lastly, in accordance with the discovery learning of Jerome Bruner in which rubric is a tool that allows the learners to discover their competencies specifically critical thinking and meta cognitive skills (Park as cited by Philominraj, et. al., 2018).

It also corresponds to Chowdhury (2019) who presented a more detailed list of benefits of rubric as a leaning tool. These benefits are as follows: rubric notifies students of expectations; it provides informative and timely feedback; helps to maintain grading consistency and fair assessment; fosters students learning.

\section{Conclusion}

Based on the findings, the following conclusions were drawn: First, both the experimental and control groups have almost similar prior knowledge on the topic about applications of the derivative. Second, the control group has improved significantly in their performance on the posttest, which shows that the traditional way of teaching math or the conventional method is effective. Third, however, the experimental group showed more significant improvement than the control group. The experimental group showed 
improvement significantly after the use of rubric as a tool in learning mathematics. Thus, the rubric is useful. Fourth, since both experimental and control groups showed an improvement, both of the teaching strategies, which are the traditional way of teaching math or the conventional method and the use of rubric in teaching math, are effective. Moreover, the use of rubric as a tool in learning Applications of Derivatives is effective in improving students' academic achievement as it teaches students to develop their understanding of procedural knowledge and can give them insights on rating their progress.

Thus, mathematics teachers and students should be trained to use rubric as a learning tool in Applications of Derivatives in Basic Calculus that focuses on problem solving. Moreover, school administrators should consider training for teachers on exploring the uses of rubrics as well as creating effective tools that would maximize students learning. Lastly, future researchers should verify the effectiveness of a rubric in another field to contribute to the pieces of evidence related to the effectiveness of rubrics as learning tools. Future researchers can conduct a study to determine if an evaluation of the students on the use of rubric as a learning tool has a significant correlation with their test performance as indicated by test scores. They can also replicate this study to other courses and year levels to either affirm or negate the findings of this study considering different groupings in the experimentation for instance, the experimentation may be done according to sexes and sections.

\section{Acknowledgment}

The researcher would like to express her deep gratitude and recognition to the people who in one-way or another have contributed to complete this study.

\section{Bibliography}

Andrade, H. \& Reddy, M. (2010). A Review of Rubric Use in Higher Education. Assessment \& Evaluation in Higher Education, 35(4), 435-448, https://doi.org/10.1080/02602930902862859

Bada, O. (2015). Constructivism Learning Theory: A Paradigm for Teaching and Learning. IOSR Journal of Research \& Method in Education (IOSR-JRME), 5(6), 2320-7388. Retrieved from http://www.iosrjournals.org/iosr-jrme/papers/Vol-5\%20Issue6/Version-1/I05616670.pdf

Behera, D. (2017). Assessment of Students' Learning through Constructive Approach. Retrieved from https://www.researchgate.net/publication/331134741 Assessment of Students\%2 7 Learning through Constructive Approach

Bradbury, J. (2010). Why is Teaching with Problem Solving Important to Student Learning? NCTM, 13(12), 1-6.

Brookhart, S. (2013). How to Create and Use Rubrics and Why Are They Important? ASCD: Professional Learning \& Community for Educators. Retrieved from http://www.ascd.org/publications/books/112001/chapters/What-Are-Rubrics-andWhy-Are-They-Important\%C2\%A2.aspx

Callaman, R., \& Itaas, E. (2020). Students' mathematics achievement in Mindanao context: A meta-analysis. JRAMathEdu (Journal of Research and Advances in Mathematics Education), 5(2), 148-159. https://doi.org/10.23917/jramathedu.v5i2.10282 
Chowdhury, F. (2019). Application of Rubrics in the Classroom: A Vital Tool for Improvement in Assessment, Feedback and Learning. International Education Studies, 12(1), 61-68. https://doi.org/10.5539/ies.v12n1p61

Clabaugh, G. K. (2010). The Educational Theory of Jerome Bruner: A Multi-Dimensional Analysis. $\quad$ Retrieved from http://www.newfoundations.net/GALLERY/BrunerTheory.pdf

Cox, G., Morrison, J. \&Brathwaite, Beverley. (2015). The Rubric: An Assessment Tool to Guide Students and Markers. In 1st International Conference on Higher Education Advances, HEAd'15, Universitat Politècnica de València, València, pp. 26-32. http://dx.doi.org/10.4995/HEAd15.2015.414

Creswell, J. (2014). Research Design Qualitative, Quantitative and Mixed Methods Approaches. Thousand Oaks, CA: SAGE Publications, Inc.

Department of Education. (2019). PISA 2018 National Report of the Philippines. Retrieved from $\quad$ https://www.deped.gov.ph/wp-content/uploads/2019/12/PISA-2018Philippine-National-Report.pdf.

Donlan, K. (2014). The Usefulness of Rubrics. ESSAI, 12, Article 15. Retrieved from https://dc.cod.edu/essai/vol12/iss1/15/

Francis, J.E. (2018). Linking Rubrics and Academic Performance: An Engagement Theory Perspective. Journal University Teaching \& Learning Practice, 15(1). Retrieved from http://ro.uow.edu.au/jutlp/vol15/iss1/3

Gallego-Arrufat, M. J., \& Dandis, M. (2014). Rubrics in a secondary mathematics class. International Electronic Journal of Mathematics Education, 9(1-2), 75-84. Retrieved from https://www.iejme.com/download/rubrics-in-a-secondary-mathematicsclass.pdf

Garofalo, C., Holden, C. J., Zeigler-Hill, V., \& Velotti, P. (2016). Understanding the connection between self-esteem and aggression: The mediating role of emotion dysregulation. Aggressive Behavior. 42(1), 3-15. https://doi.org/10.1002/ab.21601

Gleason, B. L., Gaebelein, C. J., Grice, G. R., Crannage, A. J., Weck, M. A., Hurd, P., Walter, B., \& Duncan, W. (2013). Students' Critical-Thinking and Problem-Solving Abilities across a 6-Year Doctor of Pharmacy Program. American Journal of Pharmaceutical Education, 77 (8), Article 166. https://doi.org/10.5688/ajpe778166

Gulikers, J., \& Oonk, C. (2019). Towards a Rubric for Stimulating and Evaluating Sustainable Learning. Sustainability, 11(4), 969. https://doi.org/10.3390/su11040969

Gurat, M. G. (2018). Mathematical problem-solving strategies among student teachers. Journal on Efficiency and Responsibility in Education and Science, 11(3), 53-64. https://doi.org/10.7160/eriesj.2018.110302

Darling-Hammond, L., Flook, L., Cook-Harvey, C., Barron, B., \& Osher, D. (2020). Implications for educational practice of the science of learning and development. Applied Developmental Science, 24(2), 97-140, https://doi.org/10.1080/10888691.2018.1537791

Jeong, H. (2015). Rubrics in the classroom: do teachers really follow them?. Language Testing in Asia, 5(1), 6. https://doi.org/10.1186/s40468-015-0013-5

Jönsson, A. (2014). Rubrics as a way of providing transparency in assessment. Assessment \& Evaluation in Higher Education. 39(7), 840-852. https://doi.org/10.1080/02602938.2013.875117

Kinne, L., Hasenbank, J, \& Coffey, D. (2014). Are We There Yet? Using Rubrics to Support Progress Toward Proficiency and Model Formative Assessment., Grand Valley State University. EJ1052581, XI, 109-128. https://files.eric.ed.gov/fulltext/EJ1052581.pdf 
Kumar, R. (2014). Research Methodology: A Step-by-step Guide for Beginners Fourth Edition. London, UK: SAGE Publications LTD.

Malang, 0. (2016). Effectiveness of Rubric as a Learning Tool in Teaching Mathematics of Investment.College of Education. (Unpublished master's thesis).University of Southeastern Philippines. Philippines.

Manikandan, S. (2011). Measures of Central Tendency: Median and mode. Journal of pharmacology and pharmacotherapeutics, 2(3), 214.

McKenzie, J. E. (2019). Randomisation is more than a coin toss: The role of allocation concealment. BJOG: An International Journal of Obstetrics \& Gynaecology, 126(10), 1288-1288. https://doi.org/10.1111/1471-0528.15559

Muhammad, A., Lebar, O., Mokshein, S.E., Mohamed, R., Ridzwan, S., \& Khairil, L. (2018). Assessing Student Teachers' Soft Skills Using Rubrics in E-portfolio. International Journal of Academic Research in Business and Social Sciences, 8(10), 1245-1255. http://dx.doi.org/10.6007/IJARBSS/v8-i10/5295

OECD. (2017). How does PISA for Development measure mathematical literacy? PISA for Development Brief, I (February 2014), 0-1. Retrieved from https://www.oecd.org/pisa/aboutpisa/9-How-PISA-D-measures-math-literacy.pdf

Oliveros, J. C. (2014). Adversity Quotient and Problem-solving Skills in Advanced Algebra. JPAIR Multidisciplinary Research Journal, 17(1). Retrieved from http://ejournals.ph/form/cite.php?id=12385

Palmay, A. (2015). Improving the Problem Solving Performance of Struggling Learners in Mathematics. Retrieved from https://www.semanticscholar.org/paper/IMPROVINGTHE-PROBLEM-SOLVING-PERFORMANCE-OF-INP\%C3\%A1lmay/17def322cbbaaddcf689f8a9ebf9f287307c7c5a.

Panadero, E., \& Jonsson, A. (2016). Chapter 7 The Use and Design of Rubrics to Support January 1-14. https://doi.org/10.1007/978-981-10-3045-1

Philominraj, A., Bertilla, M., Ramirez-Muñoz, B. \& Fuentealba, A. (2018). The Interconnectedness between Experience and Intelligence to English Language Teaching. English Language Teaching, 11(5), 68-73. https://doi.org/10.5539/elt.v11n5p68

Pongsakdi, N., Laine, T., Veermans, K., Hannula-Sormunen, M., \& Lehtinen, E.(2016). Improving Word Problem Performance in Elementary School Students by Enriching Word Problems Used in Mathematics Teaching. Nordic Studies in Mathematics Education, 21(2), 23-44.

Raposo, M., Cebrian-de-la-Cerna, M., Martinez-Figueira, E. (2014). Electronics Rubrics to Assess Competences in ICT Subjects. European Educational Research Journal, 13(5), 584-594. https://doi.org/10.2304/eerj.2014.13.5.584

Raymond, R., Alkrisat, M., \& Hebda, T. (2018). Improving Students through Rubric Redesign. Corpus ID: 117226503. Retrieved from https://www.semanticscholar.org/paper/Improving-Student-Outcomes-throughRubric-Redesign-Raymond-Alkrisat/470253cc597d00e791cf17e32eafc61c378892f5

Reitmeier, C. A., Svendsen, L. K., \&Vrchota, D. A. (2004). Improving Oral Communication skills of students in Food science courses. Journal of Food Science Education, 3, 15-20. https://doi.org/10.1111/i.1541-4329.2004.tb00036.x

Reynolds-Keefer, L. (2010). Rubric-Referenced Assessment in Teacher Preparation: An Opportunity to Learn by Using. Practical Assessment, Research, and Evaluation, 15(1), Article 8. https://doi.org/10.7275/psk5-mf68 
Samuelson, B. L., \& Freedman, S. W. (2010). Language policy, multilingual education, and power in Rwanda. Language Policy, 9(3), 191-215. https://doi.org/10.1007/s10993$\underline{010-9170-7}$

Schneider, J. F. (2006). Rubrics for Teacher education in Community college.The Community College Enterprise, 12(1), 39-55.

Skemp, R. R. (1976). Relational Understanding and Instrumental Understanding (Reprint). Mathematics Teaching in the Middle School, 12(2), 88-95.

Sonseca, A., Sahuquillo, O., Martinez-Casas, J., Carballeira, J., Denia, F.D., \& Rodenas, J. (2015). Assessment of Oral and Written Communication Competences in the European Higher Education Area: A Proposal of Evaluation Methodologies. In $1^{\text {st }}$ INTERNATIONAL CONFERENCE ON HIGHER EDUCATION ADVANCES (HEAD'15) (pp. 29). Editorial Universitat Politècnica de València. https://doi.org/10.4995/HEAD15.2015.485

Stevens, D.D., \& Levi, A.J. (2013). Introduction to Rubrics: An Assessment Tool to Save Grading Time, Convey Effective Feedback, and Promote Student Learning (2nd Ed.). Sterling. VA: Stylus Publishing.

Tractenberg, R., Lindvall, J., Attwood, T., Via, A. (2019). The Mastery Rubric for Bioinformatics: A tool to Support Design and Evaluation of Career-spinning Education and Training. PLoS ONE, 14(11): e0225256. https://doi.org/10.1371/journal.pone.0225256.

Tupas, S. V.. (2012). Effectiveness of Problem-Based Learning Approach to the Students' Problem Solving Performance. JPAIR Multidisciplinary Research Journal, 9(1). https://doi.org/10.7719/jpair.v9i1.4.

Vygotsky, L. S. (1978). Mind in society: The Development of Higher Psychological Processes. Cambridge, MA: Harvard University Press.

Wilson, J. W., Fernandez, M. L., \& Hadaway, N. (2011). Mathematical Problem Solving, pp. 57-78. Retrieved from http://jwilson.coe.uga.edu/emt725/PSsyn/PSsyn.html

Yu, Y. H., Hu, Y. N., \& Zhang, J. S. (2013). A research on reading model of interactive children picture book application based on the theory of "zone of proximal development." Applied Mechanics and Materials, 411-414(4), 2952-2956. https://doi.org/10.4028/www.scientific.net/AMM.411-414.2952

Zhou, M., \& Brown, D. (2017). Educational Learning Theories: 2nd Edition. In Education Open Textbooks. Retrieved from https://oer.galileo.usg.edu/education-textbooks/1 